\title{
APRENDIZAGEM DA LIDERANÇA: OPINIÃO DE ENFERMEIROS SOBRE A FORMAÇÃO ACADÊMICA
}

Ana Lúcia de Assis Simões*

Neide Fávero**

SIMÕES, A.L.A.; FÁVERO, N. Aprendizagem da liderança: opinião de enfermeiros sobre a formação acadêmica.

Rev.latino-am.enfermagem, Ribeirão Preto, v. 8, n. 3, p. 91-96, julho 2000.

O propósito desse estudo foi conhecer a opinião dos enfermeiros sobre o preparo realizado durante o curso de graduação, para liderarem a equipe de enfermagem. Foram entrevistados dezessete enfermeiros vinculados a uma instituição hospitalar pública federal, que vivenciam a situação de "liderar" uma equipe de enfermagem. O material coletado foi submetido à técnica de análise temática de conteúdo. Os resultados evidenciaram que existe insatisfação em relação ao preparo acadêmico para o desempenho da função de líder. Os aspectos abordados proporcionaram reflexão sobre a necessidade de se viabilizar estratégias de ensino-aprendizagem que levem o aluno a desenvolver habilidades de liderança.

UNITERMOS: enfermagem, liderança, aprendizagem

\section{INTRODUÇÃO}

As aceleradas e sucessivas mudanças que têm ocorrido no mundo, nas últimas décadas, resultam em desafios para o homem moderno, que da mesma forma, deve promover sua adaptação e o seu desenvolvimento para acompanhar essa evolução.

Nessa perspectiva, a enfermagem está passando por um repensar e uma redefinição de funções, de maneira a assegurar seu papel e seu compromisso com a sociedade, que, nesse momento, aspira por maior qualidade na prestação da assistência à sua saúde.

Pensar em definição de papéis e atribuições faz reportar à condição multifacetária da enfermagem, que no decorrer de sua existência, veio abraçando e incorporando à sua prática, diversas funções afins, alargando e indefinindo seu quadro de responsabilidades.

Por essa razão, muitas vezes, a função do enfermeiro é entendida de maneira questionável e equivocada. Freqüentemente, ele é considerado como o assistente do médico, servindo-o e realizando as técnicas terapêuticas que ele prescreve. Para os administradores hospitalares, é visto como alguém capaz de administrar uma seção do hospital, e também, como um coordenador dos diversos serviços hospitalares. Dessa maneira, negligencia sua primária e principal responsabilidade que é a prestação de assistência de enfermagem ao cliente (KRON,1978).

Esse perfil do enfermeiro há muito tornou-se ultrapassado e decadente, pois não atende às suas próprias aspirações como pessoa e como profissional, gerando insatisfação e frustrações. Tão pouco atende ao cliente, que tem seu cuidado fragmentado, sua assistência pouco planejada e suas necessidades superficialmente atendidas. Não atende também aos anseios da sociedade, que atualmente vem reconhecendo a necessidade de educarse para exercer o direito sobre a saúde, de tornar-se responsável por ela, sendo que, para isso, deveria ter no enfermeiro um elemento facilitador e promovedor dessa educação.

MANFREDI, já em 1988, propunha uma introspecção na profissão, que propiciasse uma reflexão e uma análise da finalidade das ações dos profissionais enfermeiros, na busca de uma consolidação do seu compromisso com a sociedade. Dizia ainda que, a consolidação de uma mudança na enfermagem exigiria a formação de líderes autênticos e uma complexa busca de inovações nos serviços de enfermagem, bem como uma mudança estrutural que lhe permitisse utilizar habilidades, capacidades e motivações.

TREVIZAN et al. (1991) reconhecem que a competência em liderança cria oportunidades para a

\footnotetext{
* Doutoranda do curso de Pós-Graduação da Área de Enfermagem Fundamental da Escola de Enfermagem de Ribeirão Preto da Universidade de São Paulo. Professor Assistente junto ao Centro de Graduação em Enfermagem da FMTM

** Professor Titular junto ao Departamento de Enfermagem Geral e Especializada da Escola de Enfermagem de Ribeirão Preto da Universidade de São Paulo
} 
inovação, levando, assim, à implementação das mudanças que são necessárias à assistência de enfermagem.

Para acompanhar as novas tendências e adaptarse a elas, há que se concordar com VALIGA (1994), ao dizer que enfermeiros líderes precisam ser inteligentes, adaptáveis, flexíveis e "experts" em comunicação e processo de pequenos grupos. Precisam ser facilitadores e coordenadores mais que administradores, que simplificam, rotinizam e fragmentam o serviço. Devem ainda, estabelecer sua base de poder na competência, serem excelentes comunicadores, falando e agindo de acordo com suas convicções.

Nesse sentido, FÁVERO (1996) recomenda que é imprescindível ao enfermeiro assumir um comportamento administrativo inovador, com novas proposições gerenciais, devendo associar, aos postulados tradicionais da administração, os valores atuais, voltandose para um pensar crítico e reflexivo, com condutas criativas e inovadoras.

Sendo assim, promover o desenvolvimento das habilidades de liderança durante o processo de formação do enfermeiro, tornou-se um desafio a ser vencido pelo aluno e pela academia, evitando-se, assim, muitos dos problemas que os enfermeiros experienciam em seu trabalho que, segundo VILLALOBOS ( 1988), resultam do processo educacional.

Ressaltamos que as recomendações para o preparo do acadêmico de enfermagem em relação à liderança não são recentes. Citamos CARVALHO (1973) ao comentar a formação acadêmica do enfermeiro, destacando a importância de serem aliadas teoria e prática, com vistas a proporcionar o desenvolvimento de habilidades mentais e motoras; atitudes humanas, éticas e profissionais; e ainda, capacitar o aluno para a prestação da assistência integral de enfermagem; desenvolver habilidade de comunicação e interrelacionamento humano, bem como prepará-lo para o exercício da liderança.

Recorremos à literatura para levantar algumas referências sobre o ensino da Administração Aplicada à Enfermagem, na intenção de conhecer como o graduando está sendo preparado para assumir o papel de líder da equipe de enfermagem.

SANTOS (1985), avaliando o ensino dessa disciplina, a qual focaliza temas de Chefia e Liderança, relata o questionamento dos estudantes a respeito da formação do enfermeiro que é levado a desempenhar funções de liderança, bem como sobre as características individuais que influenciam no exercício dessa função. Para os estudantes que fizeram parte do estudo, os profissionais que não dispõem dessa habilidade, ocupamse com procedimentos eminentemente técnicos, evitando, assim, enfrentar situações que requeiram exercitar a liderança, por considerá-las estressantes, incômodas e embaraçosas.

Reforçando a importância do estudo da liderança para a função gerencial na enfermagem, SANTOS (1991) sugere que seja incentivada a abordagem desse assunto nos cursos de graduação e pós-graduação.

LUIS (1989) trata do predomínio do tradicionalismo das teorias mais antigas da administração. Quanto à liderança na prática, comenta sobre a centralização do líder, a colocação do liderado como um subalterno e a pequena ênfase na situação, além de um inter-relacionamento deficiente, complicado e tumultuado.

Em seus estudos, refletindo sobre a incorporação do modelo burocrático na prática e no ensino da enfermagem, a autora lança questionamentos a propósito da visão de homem na qual as escolas se apoiam para a preparação do aluno. Conclui, frente às várias questões, serem necessárias mudanças nos aparelhos formadores, para que as mesmas ocorram na prática; e ainda, que novos padrões sejam criados nas escolas, a fim de formar um profissional mais flexível, independente e criativo.

A proposta de formação do enfermeiro também é comentada por ANDRADE et al. (1990), que a colocam como um entrave ao desenvolvimento da liderança nos estudantes, justificando pela falta de estímulos ao aluno, que o desafiem a se tornar um líder, e ainda, por não criar oportunidades que favoreçam a expansão das potencialidades com autonomia. Atribui às características do processo ensino-aprendizagem, a ocorrência de tais fatos.

Como conseqüência das deficiências apresentadas pelas instituições formadoras em preparar o aluno para assumir a função de liderança, constata-se a ocorrência de frustração e desencantamento do enfermeiro com relação a essa atividade, como também uma desilusão por parte do empregador, que alimenta a expectativa de contratar um profissional apto a atuar com capacidade de liderança (Douglass apud TREVIZAN \& MENDES, 1988).

Estudo realizado por ANTUNES (1991) registra um levantamento realizado nas Escolas de Enfermagem da região sudeste, apresentando um panorama de como tem se efetuado o ensino de conteúdos administrativos nestas escolas. Após a análise do material levantado, a autora verificou que na maioria dos conteúdos da disciplina Administração aplicada à Enfermagem, daquelas escolas, predomina a formação de um perfil de enfermeiro voltado para exercer uma supervisão técnicoadministrativa da equipe de enfermagem, preocupado com a organização do espaço hospitalar, fundamentado na escola tecno-burocrática. Os conteúdos relacionados ao gerenciamento e à liderança dos serviços de enfermagem são expressos e enfatizam as características do chefe e o processo de tomada de decisão. 
A autora conclui que ao assumir a prática, o enfermeiro reproduz o modelo tradicionalista da administração científica, tornando-se um especialista em dividir o trabalho em tarefas, direcionando a supervisão para o controle do subordinado, em detrimento da qualidade e resolutividade da assistência de enfermagem. E ainda, "formado para assistir e domesticado para controlar, o enfermeiro também perde o rumo da integralidade da assistência ao usuário" (ANTUNES, 1991, p.66).

Entendemos a liderança como um processo coletivo para o qual é necessária a integração de esforços individuais, buscando alcançar objetivos definidos e compartilhados pelo grupo. Sendo assim, é imprescindível ao enfermeiro reconhecer a importância e o valor de cada elemento da equipe, bem como as demandas situacionais.

Como afirma MOTTA (1991), atualmente acredita-se que a maioria das pessoas pode se tornar líder, pois é possível aprender as habilidades de liderança, através de ensinamentos e de experiências de vida.

COVEY (1996) refere que o aprendizado da liderança acontece através da observação de tendências, da percepção e antecipação das necessidades do mercado, da avaliação dos sucessos e erros do passado, e da absorção das lições que a consciência e os princípios ensinam.

Treinamentos ultrapassados de liderança são questionados por BOLT (1996) que propõe a estrutura holística e tridimensional, a qual pressupõe o desenvolvimento de habilidades profissionais, de liderança e de eficácia pessoal; refere ainda que a liderança é uma combinação de competência e caráter.

O líder, sendo considerado um agente de mudanças, além de adquirir novos conceitos e habilidades, deverá desaprender também o que não é mais útil à organização (SCHEIN, 1996).

Nesse sentido, para que o enfermeiro possa exercer efetivamente a liderança, deverá submeter-se a uma transformação pessoal e profissional, aprimorando suas habilidades técnicas, científicas e interpessoais.

Dessa forma, partindo-se da premissa que, em todo processo de transformação está implícito um novo aprendizado, e, considerando o enfermeiro, um agente de transformação, reforça-se a necessidade de que ele aprenda e desenvolva habilidades de liderança, tais como: buscar o auto-conhecimento, reconhecendo suas potencialidades e limitações; manter bom relacionamento interpessoal; comunicar-se com simplicidade e clareza; delegar poderes, a fim de conseguir o melhor de cada um; incentivar a equipe, valorizando e recompensando comportamentos; ser facilitador e inspirador mais que controlador; ter clareza da filosofia, das crenças e dos valores essenciais da profissão.
Considerando o exposto, esse estudo tem o objetivo de verificar a opinião do enfermeiro sobre o preparo durante o curso de graduação, para o desempenho da função de liderar a equipe de enfermagem.

\section{TRAJETÓRIA METODOLÓGICA}

O estudo foi desenvolvido em uma instituição hospitalar pública federal, localizada no interior de Minas Gerais, na micro-região do Triângulo Mineiro.

Os sujeitos da pesquisa foram 17 enfermeiros responsáveis pelas unidades de internação da referida instituição, que atuam diretamente com as equipes de enfermagem.

Optamos por enfermeiros recém formados ou que concluíram a graduação nos últimos quatro anos, pois consideramos que os primeiros anos de atuação profissional do enfermeiro são marcados pela vivência de situações diversas, dentre elas a de liderar uma equipe de enfermagem, constituindo-se, assim, num dos períodos mais difíceis da vida do profissional que necessita de uma série de adaptações relativas às novas funções e compromissos assumidos.

A coleta das informações foi realizada durante o mês de janeiro de 1997, através de entrevista que contemplava a seguinte questão: Qual a sua opinião em relação ao que foi oferecido durante o curso de graduação, sobre a função de liderar a equipe de enfermagem?

Cada entrevista foi precedida de solicitação de consentimento dos enfermeiros em participar da pesquisa; tendo sido esclarecida a finalidade, os objetivos e a importância para a prática profissional, sendo também assegurado o caráter confidencial das informações.

As entrevistas foram realizadas com a utilização de um gravador e tiveram duração média de 20 minutos. Posteriormente, foram transcritas na íntegra, respeitandose a terminologia utilizada pelos entrevistados.

O material coletado foi submetido à técnica de análise temática de conteúdo, segundo BARDIN (1991). Seguindo os passos propostos pela referida autora, procedemos à organização do material, realizando uma leitura flutuante a fim de tomar conhecimento do conteúdo das informações.

Durante a fase de exploração do material, que se refere à análise propriamente dita, realizamos a codificação, a categorização e a quantificação das informações. $\mathrm{O}$ conteúdo das mensagens foi fracionado através de recortes, promovendo a seleção de segmentos, com base nos temas emergentes, destacando-se, assim, as unidades de registro que foram agrupadas em 
categorias, de acordo com a freqüência de aparição nos discursos.

Finalmente, conforme recomendação de BARDIN (1991), passamos à interpretação dos resultados, submetendo-os a operações estatísticas simples (percentagens) e a interpretações, de acordo com o objetivo proposto e o referencial bibliográfico.

\section{APRESENTAÇÃO E DISCUSSÃO DOS RESULTADOS}

Dentre as 97 unidades de registro destacadas dos discursos dos sujeitos, que emitiram suas opiniões sobre o aprendizado da liderança, 34 (35\%) unidades mostram que alguns se sentem adequadamente preparados para assumir a liderança na enfermagem, enquanto, 63 (65\%) unidades de registro revelam um descontentamento em relação ao processo ensino-aprendizagem, declarando despreparo para o desempenho da função de líder.

Assim sendo, as unidades de registro foram agrupadas em duas categorias, a saber: Categoria I INSATISFATÓRIO, reunindo as unidades que mostram o descontentamento dos entrevistados quanto ao que foi oferecido durante o curso de graduação em enfermagem, para o desenvolvimento da liderança, e Categoria II SATISFATÓRIO, abrangendo as unidades que revelam satisfação desses profissionais em relação ao aprendizado da liderança.

A categoria INSATISFATÓRIO contemplou o maior número de unidades de registro. Tal resultado levanos a questionar como tem se efetivado o ensino de conteúdos sobre a liderança nos cursos de graduação em enfermagem, uma vez que as falas refletem uma inadequação do processo ensino-aprendizagem, demonstrando repercutir na prática profissional.

Estudos contemporâneos sobre liderança afirmam que líderes podem ser formados, independentemente das características pessoais que possuam. Para MOTTA (1991), é possível aprender as habilidades para a liderança através de ensinamentos e de experiências de vida.

Com essa visão, pode-se perceber o papel desafiador e a responsabilidade que as instituições de ensino têm em formar e lançar no mercado de trabalho, profissionais devidamente preparados para assumir a função de liderar a equipe de enfermagem.

Considerando que uma pessoa, mesmo despida de habilidades especiais, pode tornar-se um líder, faz-se então necessário que os órgãos formadores se sensibilizem e efetivem um processo ensinoaprendizagem, o qual possibilite o desenvolvimento de habilidades próprias da função, oferecendo oportunidades de vivenciar situações práticas e, conseqüentemente, enriquecendo as experiências pessoais. Esta premente necessidade é reforçada pelas falas dos enfermeiros entrevistados:

\section{... faltou um pouco de técnica, de preparo, de vivência... \\ ... não houve situações práticas, nem exemplos de liderança... \\ ... os estágios foram poucos... \\ ... não consegui exercitar a liderança...}

Apesar de alguns estudos evidenciarem a possibilidade de formação de líderes, os relatos revelam um número significativo de enfermeiros insatisfeitos com o ensino, despreparados e inseguros quanto ao desempenho da liderança. Frente a essa situação, selecionamos alguns relatos que expressam essa insatisfação dos profissionais:

\section{... na graduação não ensinou isso...}

... o ensino da liderança ficou falho...

... poderia ter sido melhor...

... saí da faculdade muito insegura em relação a esta função...

A insatisfação encontrada nos profissionais em relação à aprendizagem e ao desenvolvimento das habilidades de liderança, durante a graduação, leva a um repensar sobre os currículos de enfermagem e sobre como tem sido oferecida, ao estudante, a oportunidade de desenvolver atitudes críticas e reflexivas, a criatividade e a consciência de que devem atuar como agentes de transformação.

Mediante as falhas alegadas no decorrer do curso de graduação, percebemos que alguns enfermeiros verbalizam interesse e disposição para adquirir as habilidades necessárias ao líder, valorizando suas experiências pessoais, enfatizando a importância do aprendizado na prática profissional. Justificam, ainda, que têm tentado suprir as falhas detectadas ao longo do curso, através da experiência adquirida no dia-a-dia, desempenhando as atividades profissionais. As falas a seguir relacionam-se a essa afirmativa:

... tenho conseguido isso trabalhando...

...na prática, no dia-a-dia a gente aprende... ...tenho desenvolvido a liderança nestes anos de experiência...

Sabemos que a prática profissional é frutífera e enriquece sobremaneira os conhecimentos teóricos, porém, cabe à escola, enquanto órgão formador, proporcionar condições de ensino que subsidiem e tornem esse processo menos árduo para o enfermeiro em seu cotidiano profissional.

A necessidade de uma reestruturação substancial no processo ensino-aprendizagem dos cursos de enfermagem é defendida por diversos autores, dentre outros: MANFREDI (1988); VILLALOBOS (1988); 
LUIS (1989); ANDRADE et al. (1990) e INFANTE (1992), que consideram uma formação adequada, como essencial à prática de uma liderança eficaz.

Com relação à categoria SATISFATÓRIO, que alcançou apenas $35 \%$ do total das unidades de registro que se referiam ao aprendizado da liderança, ficou claro que, para alguns poucos enfermeiros, a escola cumpriu com seu papel de formadora, sentindo-se estes, adequadamente preparados para o desempenho da função de líder.

... fui muito bem preparada...

...até então eu não tinha conhecimentos sobre

liderança....

... fomos preparados para ser líderes...

... foi muito bom...

Ao que parece, considerando-se bem preparados para o exercício da liderança, os enfermeiros demonstram estar satisfeitos com os métodos adotados, com as condições oferecidas e com as situações vivenciadas durante o período de graduação, e ainda, acreditam estar desenvolvendo adequadamente a liderança.

Consideramos pertinente destacar algumas falas que denotam uma posição de neutralidade, ou mesmo de conformismo, frente ao preparo para liderar a equipe de enfermagem:

... não tenho o que me queixar...

... não estou me saindo mal...

Em algumas descrições, percebemos que houve por parte dos cursos de graduação, uma preocupação com o repasse de conteúdos teóricos a respeito da liderança, fazendo com que os entrevistados sintam-se preparados apenas "teoricamente" para liderar a equipe de enfermagem. As falas a seguir revelam essa opinião:

... contribuiu na teoria...

... fomos bem preparados teoricamente... ...deu uma boa base teórica..

Considerando o enfoque teórico do aprendizado, achamos oportuno ressaltar uma pertinente colocação feita por um dos entrevistados:

... você pode até ser bem preparado

teoricamente, mas você não vive a enfermagem na teoria e sim na prática...

Essa expressão levou-nos a refletir sobre a importância de se aliar teoria à prática, perpassada nas entrelinhas do discurso, o qual também retrata a dicotomia vivenciada na realidade pelo profissional enfermeiro.
Tal posicionamento vem corroborar a necessidade de proporcionar ao estudante de enfermagem a oportunidade de observar a realidade, de vivenciar situações práticas de liderança, estimular a reflexão, a iniciativa e a busca de soluções inovadoras para os problemas cotidianos.

\section{CONSIDERAÇÕES FINAIS}

Os resultados da análise permitiram constatar a opinião dos enfermeiros em relação ao que foi oferecido sobre o tema Liderança, pela instituição de ensino à qual estiveram vinculados, evidenciando que existe insatisfação por parte da maioria dos profissionais entrevistados frente a abordagem realizada.

Tal insatisfação ficou caracterizada nos relatos que registram falhas no processo ensino-aprendizagem da liderança em enfermagem, compreendendo tanto a abordagem teórica do tema, quanto a falta de modelos de liderança e de oportunidades para vivenciar situações práticas. Os enfermeiros referem tentar suprir essas falhas, no dia-a-dia de trabalho, através das experiências vividas. Esse fato sugere a realização de outras investigações, com o objetivo de encontrar meios que viabilizem uma formação acadêmica que leve à satisfação e competência profissional.

Ainda no que se refere à aprendizagem da liderança, a pesquisa reforçou a crença de que a formação de líderes é um desafio a ser perseguido, não apenas pelos órgãos de ensino, como também por todos os profissionais enfermeiros, pois trata-se de uma condição essencial para a visualização de um futuro com novas alternativas e propostas de atuação, podendo-se, assim, vislumbrar maior prestígio e valorização profissional.

Embora a temática que envolve a liderança seja profunda, acreditamos que esses resultados constituem pontos importantes a serem refletidos e analisados por enfermeiros e por educadores, na busca de soluções para a problemática citada, tendo em vista a formação de enfermeiros com maior satisfação profissional e com mais habilidade em liderança; empregadores mais satisfeitos com o desempenho desse profissional e, acima de tudo, clientes assistidos com um padrão de atendimento com a qualidade e o respeito a que têm direito.

\section{LEARNING ON LEADERSHIP: NURSES OPINION ABOUT THEIR ACADEMIC EDUCATION}

The purpose of the present study was to identify nurses opinion about aspects of their academic undergraduate education directed to form leaders of the nursing team. Therefore, authors interviewed 17 nurses from a public federal hospital who experience the condition of being staff leaders. The collected material was analyzed through the technique of content analysis. Results evidenced a dissatisfaction concerning their academic training on leadership. The approached aspects showed the importance of 
a reflection about the need of teaching-learning strategies that allow students to develop leadership skills.

\title{
APRENDIZAJE DEL LIDERAZGO: OPINIÓN DE ENFERMEROS SOBRE LA FORMACIÓN ACADEMICA
}

\begin{abstract}
El propósito de ese estudio fue conocer la opinión de los enfermeros la capacitación recibida durante el curso de graduación, para el liderazgo del cuadro de enfermería. Fueron entrevistados diecisiete enfermeros vinculados a una institución hospitalaria pública gubernamental, que viven la situación de "liderazgo" de un cuadro de enfermería. El material recolectado fue sometido a la técnica de análisis de contenido. Los resultados evidenciaron que existe insatisfacción en relación con la preparación académica para el desempeño de la función de líder. Los aspectos abordados proporcionaron reflexiones sobre la necesidad de desarrollar estrategias viables de enseñanza-aprendizaje llevando al alumno a desenvolver habilidades de liderazgo.
\end{abstract}

TÉRMINOS CLAVES: enfermería, liderazgo, aprendizaje

\section{REFERÊNCIAS BIBLIOGRÁFICAS}

01. ANDRADE, T.G.C.S. de et al. O enfermeiro e sua percepção sobre liderança em enfermagem. In: SIMPÓSIO BRASILEIRO DE COMUNICAÇÃO EM ENFERMAGEM, 2, Ribeirão Preto, 1990. Anais. Ribeirão Preto: Escola de Enfermagem de Ribeirão Preto/USP, 1990. p. 249-270.

02. ANTUNES, M.J.M. O ensino de administração da assistência de enfermagem nas escolas públicas da região sudeste. Rev. Paul. Enfermagem, v. 10, n. 2, p. 58-67, 1991.

03. BARDIN, L. Análise de conteúdo. Lisboa: Edições 70, 1991.

04. BOLT, J.F. Desenvolvendo líderes tridimensionais. In: HESSELBEIN, F.; GOLDSMITH,M.; BECKHARD,R. (eds.). O líder do futuro: visões, estratégias e práticas para uma nova era. Trad. Cyntia Azevedo. São Paulo: Futura, 1996. Cap. 17 , p. $169-80$.

05. CARVALHO, A.C. de. Enfermagem e enfermeiras. Rev. Esc. Enfermagem USP, v. 7, n. 1, p. 7-13, 1973.

06. COVEY, S.R. Três funções do líder no novo paradigma. In: HESSELBEIN, F.; GOLDSMITH,M.; BECKHARD,R. (eds.). O líder do futuro: visões, estratégias e práticas para uma nova era. Trad. Cyntia Azevedo. São Paulo: Futura, 1996. Cap. 16, p. 159-168.

07. FÁVERO, N. O gerenciamento do enfermeiro na assistência ao paciente hospitalizado. Ribeirão Preto, 1996. 92p. Tese (Livre-Docência) - Escola de Enfermagem de Ribeirão Preto, Universidade de São Paulo.

08. INFANTE, N.B. Liderasgo en enfermeria: posibilidades y tendencias. Educ. Med. Salud, v. 26, n. 2, p. 242-50, 1992.
09. KRON, T. Manual de enfermagem. 4. ed. Rio de Janeiro: Interamericana, 1978.

10. LUIS, M.V. A enfermagem e o conhecimento dos conceitos de liderança, motivação, comunicação e mudança. Acta Paul. Enfermagem, v. 2, n. 4, p. 111-122, 1989.

11. MANFREDI, M. $i$ Es necesario promover el liderazgo en enfermería para el avance de los programas docente-asistenciales?. Educ. Med. Salud, v. 22, n. 1, p. 3-11, 1988.

12. MOTTA, P.R. Gestão contemporânea: a ciência e a arte de ser dirigente. Rio de Janeiro: Record, 1991.

13. SANTOS, I. Liderança em enfermagem: um questionamento para o enfermeiro. /Trabalho apresentado no 37o. CBen. Recife, Pe., 1985./

14. SANTOS, I. Estilos gerenciais dos enfermeiros na área de recuperação da saúde. Rev. Bras. Enfermagem, v. 44, n. 2, p. 76-88, 1991.

15. SCHEIN, E.H. Liderança e cultura organizacional. In: HESSELBEIN, F.; GOLDSMITH, M.; BECKHARD, R. (eds.). O líder do futuro: visões, estratégias e práticas para uma nova era. Trad. Cyntia Azevedo. São Paulo: Futura, 1996. Cap. 6, p. 81-90.

16. TREVIZAN, M.A.; MENDES, I.A.C. O líder como fonte central de comunicação. In: SIMPÓSIO BRASILEIRO DE COMUNICAÇÃO EM ENFERMAGEM, 1, Ribeirão Preto, 1988. Anais. Ribeirão Preto: Escola de Enfermagem de Ribeirão Preto/USP, 1988. p. 297-309.

17. TREVIZAN, M.A. et al. Liderança do enfermeiro no contexto hospitalar. Rev. Bras. Enfermagem, v. 44, n. 1, p. 55-59, 1991.

18. VALIGA, T.M. Leadership for the future. Holist Nurs. Pract., v. 9, n. 1, p. 83-90, 1994.

19. VILLALOBOS, M.M.D. de. El desarollo del liderazgo y la educación en enfermería. Educ. Med. Salud, v. 22, p. 3-11, 1988. 